\title{
DYNAMICS OF HISTOLOGICAL CHANGES IN TRAUMATIZED LIVER TISSUES IN THE ABSENCE OF ALCOHOL INTOXICATION
}

\author{
Olena P. BABKINA ${ }^{1^{\star}}$, Dmytro 0. MATYUKHIN ${ }^{2}$, Svitlana I. DANYLCHENKO ${ }^{3}$, \\ Igor. S. KOROBKO², Oleksiy 0. GALMYZ ${ }^{4}$, Andriy A. CHERNOZUB ${ }^{3}$, Illia I. VAKO ${ }^{3}$ \\ ${ }^{1}$ Department of Forensic Medicine and Medical Law, OO Bohomolets National Medical University, Kyiv, \\ Ukraine \\ 2 Department of Pathological Anatomy, Forensic Medicine and Medical Law, Luhansk State Medical \\ University, Rubizhne town, Luhansk region, Ukraine \\ ${ }^{3}$ Department of Medical and Biological Basics, Petro Mohyla Black Sea National University, Mykolaiv, \\ Ukraine \\ ${ }^{4}$ Department of Surgery, Lugansk Regional Clinical Oncologic Dispensary, Kremennaya, Ukraine \\ Received 24 Apr 2019, Accepted 29 May 2019 \\ https://doi.org/10.31688/ABMU.2019.54.2.04
}

\section{Abstract}

Introduction. Liver injury is an important cause of death in patients with traumatic injuries.

The objective of the study. To study the dynamics of changes in histological parameters of injured liver tissues in case of mechanical trauma, depending on the time of damages in the absence of alcohol intoxication.

Materials and methods. We examined liver tissue of 52 individuals (38 men and 14 women) aged 20-60 years, who died at known and unknown time in the absence of alcohol in the blood in the Lugansk region of Ukraine. The cause of death was a mechanical trauma. The study was conducted by means of histological, histochemical methods, statistical analysis.

Results. Regular histological changes were observed in the area of injured liver tissue. These changes directly depend on the time elapsed since the caused damage. Usage of the histological method was proved to

\section{RésumÉ}

Dynamique des modifications histologiques dans les tissus hépatiques lésés en l'absence d'intoxication alcoolique

Introduction. Les lésions hépatiques sont une cause importante de décès chez les patients présentant des lésions traumatiques.

Le but de la recherche. Étudier l'évolution des modifications des paramètres histologiques de tissus hépatiques endommagés lors de lésions mécaniques en fonction du type de la lésion en l'absence d'intoxication alcoolique.

Matériel et méthodes. Nous avons examiné le tissu hépatique de 52 hommes et femmes (38 hommes et 14 femmes) âgés de 20 à 60 ans, décédés à une heure connue et inconnue en l'absence d'alcool dans le sang. L'étude a été réalisée à l'aide de méthodes histologiques, histochimiques et d'analyses statistiques dans 
be expedient for determining the time of injury, both in the isolated liver injury and in combined injuries of the abdominal organs. This method allows to increase the objectivity of the results determining the time of injury.

Conclusions. The study determined changes of histological parameters of liver tissue depending on the time of injury, time of death, presence of traumatic illness, which can help in solving the question on the injury duration.

Keywords: liver, trauma, alcohol intoxication, time of trauma, histological parameters.

\section{INTRODUCTION}

The steady increase of the number of military conflicts and man-made disasters has led to an annual increase by $1 \%$ of the number of injured and deaths from injuries among the population in Ukraine $\mathrm{e}^{1-3}$. The Operation of the United National Forces for National Security and Defense, Resistance and Restraint of Armed Aggression of the Russian Federation in Donetsk and Lugansk Oblast was launched on March 30, 2018 in the format of the Anti-Terrorist Operation in the Region, which was introduced in 2014. According to the UN Office report, more than 2500 citizens were killed and more than 9000 were injured in eastern Ukraine over the past four years ${ }^{4-6}$. The number of dead and injured continues to increase every day, therefore, the question of the nature, mechanism, time of injuries, the morpho-functional state of the internal organs of the injured, and the impact of alcohol intoxication remains relevant.

Liver is injured more frequently than other internal organs, and its closed damage is accompanied by difficulties in diagnosis and high mortality. The high frequency of liver injury is due to its close topographical position near the abdominal wall, from one side, and near the edge arch from the other side, its large size and weight, slight change in its position at the time of injury, degree of blood supply, durability of the ligament.

The formation of liver injury also depends on the intra-abdominal pressure, the tone of the abdominal muscles, the close placement of the diaphragm, the state la région de Lougansk en Ukraine sur les victimes d'un traumatisme mécanique et qui était la cause de la mort.

Résultats. L'étude a démontré que des modifications histologiques régulières sont observées dans la zone du tissu hépatique lésé qui dépendent directement du temps écoulé depuis la lésion. Il est prouvé que l'utilisation de la méthode histologique pour déterminer le moment de la lésion dans le cas d'un trauma isolé du foie et dans le cas de lésions combinées des organes abdominaux, est justifiée car elle permet d'augmenter l'objectivité des résultats lors de la détermination de l'historique de la lésion.

Conclusions. L'étude a identifié des modifications des paramètres histologiques du tissu hépatique en fonction de l'historique de la lésion, du moment du décès, de la présence d'une maladie traumatique, ce qui peut aider à préciser l'historique de la lésion.

Mots-clés: foie, lésion, intoxication alcoolique, histoire de la lésion, paramètres histologiques.

of the stomach and intestines, etc ${ }^{7-10}$. Information on the frequency of liver damage in case of mechanical injury is controversial in literature sources. Some authors, when studying the features of blunt trauma, found out that the frequency of liver damage was $58.7 \%$ among other injuries of internal organs $s^{11 \cdot 13}$. At the same time, it was noted that the right liver was damaged in $62.2 \%$ of the cases and its left lobe was injured in $10.7 \%$ of cases, both parts were simultaneously damaged in $15.5 \%$ of cases $^{14-17}$. In $41.2 \%$ of the cases, the liver was damaged by blunt objects ${ }^{14-16}$. The shock-breaking mechanism result and the body compression were causes of the liver damage in $28.8 \%$ and $29.4 \%$ of cases, respectively ${ }^{18-20}$. The diaphragmatic surface of the liver was damaged in $45.5 \%$ of the cases, the upper and lower surfaces were damaged in $37 \%$ of cases $^{21223}$.

Thus, according to Sapozhnikova ${ }^{24}$, the frequency of liver injuries among closed abdominal traumas was $25 \%$; according to other authors, liver injury occurred in $35-50 \%$ of the cases ${ }^{25-27}$. Baramia et a ${ }^{27-30}$ noted that liver damage was detected in $27.7 \%$ of closed blunt body injuries, $90.1 \%$ of them in people of working age ${ }^{32-34}$.

The frequency of the liver damage caused under different circumstances was uneven. The most frequent are domestic injuries, road accidents, and falls from the height, injuries at work, and others. Some authors found that $45.1 \%$ of liver injuries were the result of an accident, $39.4 \%$ of cases were falls from height, $15.5 \%$ happened in the household ${ }^{31.33}$. In cases of falling from height, abdominal organs were damaged in $69.5 \%$ of cases, the liver was among them in $62.5 \%$ 
of cases according to some authors and in $24.7 \%$ of case according to other authors ${ }^{34-36}$. The liver is often traumatized in transport accidents (19.5\% of the observed), especially in car accidents. Kymbar et al ${ }^{34}$ noted that the frequency of liver injuries was $28.4 \%$ among cases of mechanical injury, where falling from height occurred in $35.4 \%$ of cases, traffic accidents occupied $44.1 \%$, blunt objects injuries comprised $8.3 \%$. The authors noted that liver injuries were often combined with damage to other organs of the abdominal cavity and retroperitoneal space. The peculiarity of liver injuries is determined by the prevalence of damage to its parenchyma and the preservation of the capsule, while the mechanism of injury development does not affect the damage so much.

The objective OF THE STUdy was to evaluate the dynamics of changes in histological parameters of injured liver tissues in case of mechanical trauma, depending on the time of damages, in the absence of alcohol intoxication.

\section{Materials AND Methods}

We examined the liver tissue of 52 individuals (38 men and 14 women), aged from 20 to 60 years, who died at known and unknown time, in the absence of alcohol in the blood and were subject to an autopsy in the Department of Forensic Medical Examination of the Lugansk region in Ukraine. The cause of death was a mechanical trauma. The collection of tissues of traumatized organs was stored in the morgue at air temperature from +16 to $25^{\circ} \mathrm{C}$, and relative humidity of $40-60 \%$. In the course of research we used histological and histochemical methods to detect the dynamics of regeneration processes of histological parameters of injured liver tissues and carried out statistical analysis of the obtained results.

The work was carried out in accordance with the requirements of the "Instruction on conducting forensic medical examination" (Order of the Ministry of Health of Ukraine No. 6 dated January 17, 1995), in accordance with the requirements and norms, the standard provisions on ethics of the Ministry of Health of Ukraine No. 690 dated September 23, 2009, "The procedure for the removal of biological objects from the dead, whose bodies are subject to forensic examination and pathological anatomical investigation, for scientific purposes“ (2018).

\section{Results}

According to our data, the histological examination of liver damage in the victims of a mechanical trauma, in the absence of alcoholic intoxication, has found out that with liver injury up to 1 hour, there were primarily reactive changes in the periphery of injuries, namely, the Diss space was unevenly enlarged, the hepatic trabeculae were sometimes discoplexed, the part of hepatocytes was replaced by small rounded cavities in the center of particles, most hepatocytes had light fine-grained cytoplasm; there occurred small-focal dystrophy. We also observed small- and large-vacuolar hepatocyte hydropic dystrophy and moderate edema mainly in the central parts of the lobules. Characterizing the degree of liver blood flow, we observed the lack of blood supply in the tissues, uneven blood filling of blood vessels in the investigated sections, aggregation of erythrocytes, and leukostasis in the lumen of individual vessels. It should be noted that most hepatocytes in the cytoplasm did not have deep raspberry color (glycogen), which was well observed during histochemical reactions. Regular changes developed after 1.5-2 hours: hepatic trabeculae in many fields of view were compressed, intervertebral spaces were widespread, the intensification of degenerative changes in hepatocytes was manifested in the appearance of small and large-vacuolar hepatocyte hydropic dystrophy, not only in the central parts of the lobules, but also at the periphery, closer to the portal tract, there was increased the proportion of hepatocytes with light foamy cytoplasm. In addition, edema was increased, bilirubin began to accumulate in the cytoplasm of hepatocytes, there was a mild infiltration of portal paths by lymphocytes in the form of granules of brown color. Lack of blood supply in the tissues of the liver tissue still remained. Vessels had uneven blood filling, with red cell aggregation, plasma separation and leukostasis in the lumen of individual vessels, as shown in Figure 1. Two hours after liver damage, the histological picture was similar to the above, but with increases in swelling, dystrophic changes, and the accumulation of bilirubin hepatocytes in the cytoplasm. There was a discomplection of the hepatic trabeculae, and decreases in the amount of glycogen. There were isolated lymphocytes between the hepatic trabeculae (Figure 2). Morphological changes in the liver with 2-4 hours duration of damage were somewhat different from changes in the first hour after the injury. Dystrophic changes, edema, spasm of the arteries, and hepatic trabeculae discompletion were increased. Thus, along with the increasing of dystrophic changes, the partial structure of the liver was sharply disturbed, all hepatocytes were virtually replaced by small ones, and in large part by large vacuoles. It means that there was a total small- and large-vacuolar hepatocyte hydropic dystrophy, both in the central parts of the lobes and in the portal tracts; with a dislocation of the hepatic trabeculae, increased edema and the appearance of 
lymphocytic infiltration (insignificant) between the portal lobes, disturbance of circulation in the form of spasm of arteries, expansion of vessels of portal paths, with plasma separation in vascular lungs. In this time interval, injuries to the intradile capillaries were enlarged, their walls were thickened due to edema accompanied by an erosion stasis in the lumen of capillaries, whereas in the lumen of large arteries in portal tracts there was a lack of erythrocytes with only plasma present, indicating the appearance of this time interval vascular reaction to injury. The hepatic trabeculae were discomplexed, the intra lobular spacing was expanded, hepatocytes were replaced by rounded haze of various sizes (Figure 3). In addition, there were other manifestations of mechanical

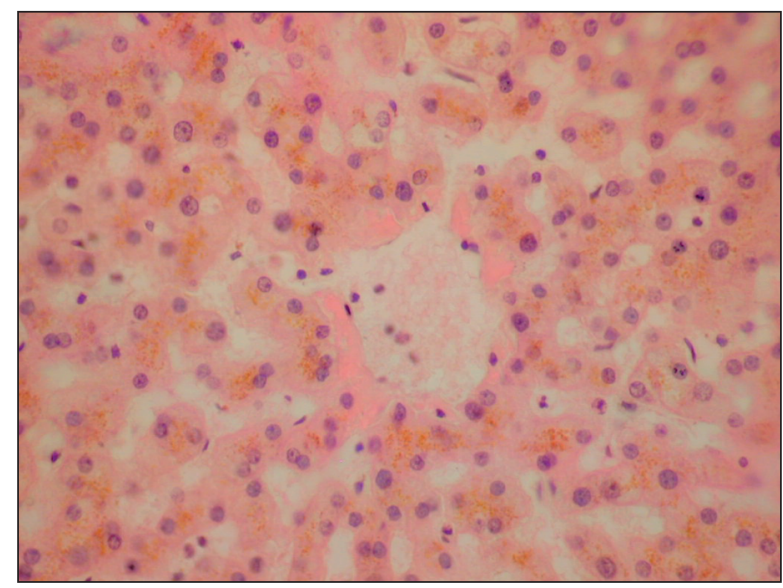

Figure 1. Growth of edema, intracellular accumulation of bilirubin pigment, small-vacuolic hepatocyte dystrophy of a 40-year-old man who died from mechanical trauma.

The duration of the injury is 1.5 hours.

Colored with hematoxylin-eosin. Scale: $\times 400$

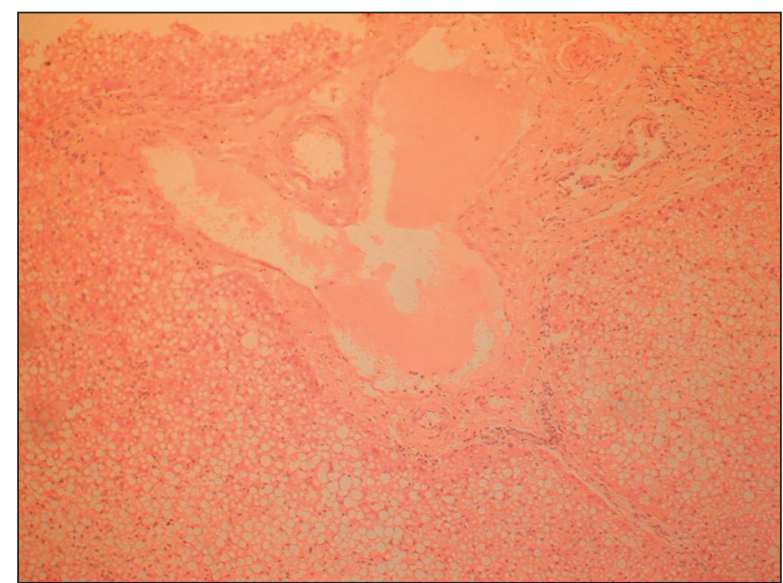

Figure 3. In the lumen of large arteries, the absence of erythrocytes with only plasma present, expressed vacuous dystrophy of hepatocytes of the liver tissue of a woman,

38 years old, who died from mechanical trauma.

The duration of injury is 4 hours.

Colored with hematoxylin-eosin. Scale: $\times 100$ damage to the liver, in the center of damage, in many fields of view, the numerous small focal hematoma areas in the form of aggregates of erythrocytes with clear contours and an admixture of single leukocytes are determined. On the periphery of hematomas, the partial structure of the liver was disturbed: interstitial spaces were unevenly distributed, the hepatic trabeculae were discomplexed, and more hepatocytes were replaced by small and large rounded vacuoles.

Vessels had uneven blood filling with aggregation of erythrocytes and leukostasis in the lumen of some of them. In the area of portal tract, small infiltrates were observed in the form of accumulation of lymphocytes (Figure 4). In addition to such hematomas in the liver parenchyma, there were parenchyma

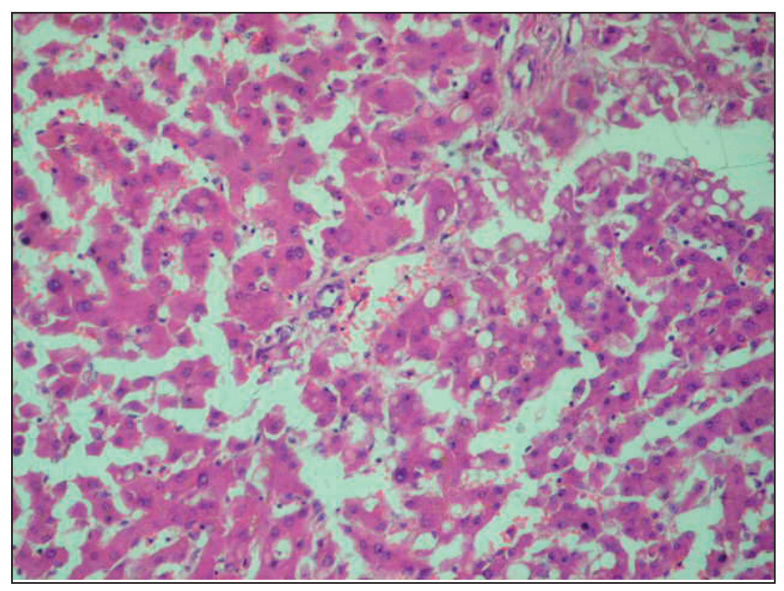

Figure 2. Significant discomplexation of hepatic trabeculae, edema, small-focal fat dystrophy of hepatocytes (centrolobular) of liver tissues of a 22 year-old man, who died from mechanical trauma. The duration of injury is 2 hours. Colored with hematoxylin-eosin. Scale: $\times 200$

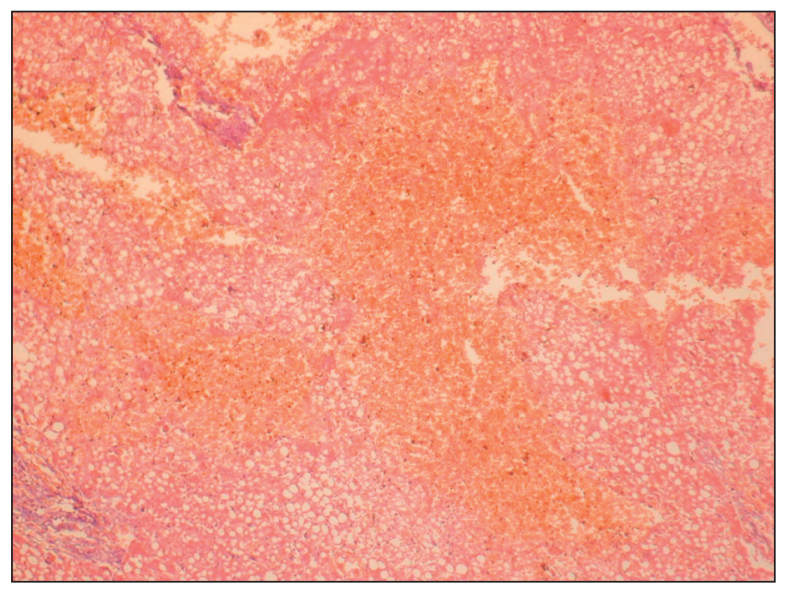

Figure 4. Multiple areas of hematomas in the liver parenchyma of a woman, 28 years old, who died from mechanical trauma. The duration of injury is 4 hours. Colored with hematoxylin-eosin. Scale: $\times 100$ 
ruptures filled with agglutinated red blood cells with clear contours of orange color in some cases. When colored according to Mallory, the protein masses were determined in the vessels, the blue-purple striped structures (fibers) were clearly seen in the cells of the ruptures, as shown in Figure 5.

When the duration of injury was 6-12 hours, we observed regular changes in the liver tissues. We also observed the lack of blood supply in the liver tissues, no erythrocytes in the liver vessels, only plasma, and vessels with uneven blood filling. Intratrabeculae spacing was expanded. Hepatocytes were with expressed dystrophic changes in the form of predominantly large-vacuolar hepatocyte hydropic dystrophy, foamy places (with fat coloring it gave a positive

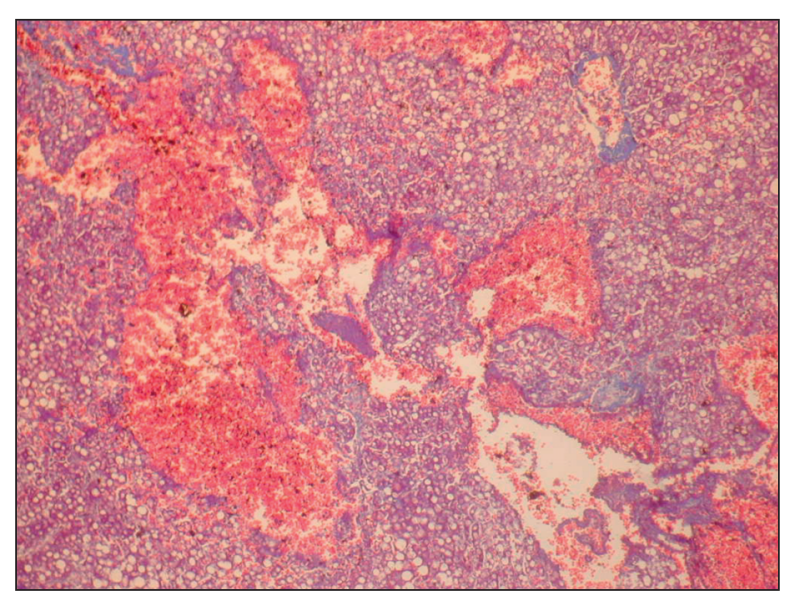

Figure 5. Multiple liver tissue ruptures with the accumulation of erythrocytes in blood vessels, fatty dystrophy of liver hepatocytes in a 34 year-old man, who died from mechanical trauma. The duration of injury is 5 hours.

Colored according to Kedrovskii. Scale: $\times 100$

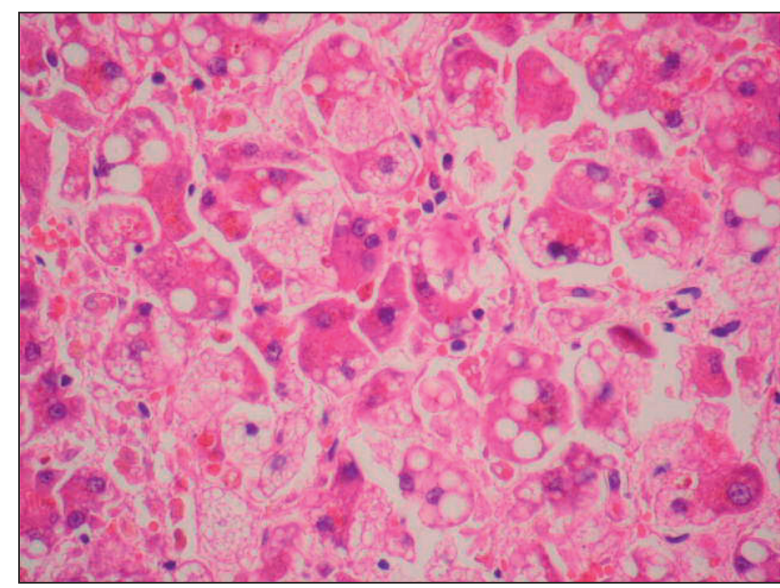

Figure 6. Along with pronounced dystrophic changes in hepatocytes (vacuolic dystrophy) there is a necrosis of individual hepatocytes in a man, 42 years old, who died from mechanical trauma. The duration of injury is 6 hours. Colored with hematoxylin-eosin. Scale: $\times 400$ reaction). We observed the accumulation of lymphocytes in the sinusoids. Morphological changes in the liver, with 5 hours duration of mechanical trauma, were primarily characterized by the appearance of necrosis in hepatic parenchyma (Figure 6).

6 hours after the trauma, hepatocytes almost completely lost glycogen, intra trabeculae spacing was expanded. We also observed severe discompensation of hepatic lobules, hepatocytes with small-and large-vacuolar cytoplasm, foamy places, uneven filling of blood vessels along with the anechoic regions with full-blooded areas. In the necrosis zone, there was a release of individual erythrocytes from the capillaries into the necrosis area, and focal intracellular cholestasis. Lymphocytic infiltration was scanty, accumulation of 5-6 lymphocytes or chains of lymphocytes in some places are observed. The glycogen granules in the cytoplasm of hepatocytes were not determined during the periodic acid Schiff (PAS) reaction. After 1-2 days of liver tissues damage, there were clear cells of necrosis with a large number of hepatocytes in the state of necrobiosis in the sites of necrobiosis and between them. After 1-2 days of injury, there were hepatocytes in neighboring with damaged areas, with marked dystrophic changes in the form of small-and large-vacuolar hydropic dystrophy, with pronounced diffuse cholestasis, and insignificant infiltration (in the form of chains from 2 to 7 ), mainly from small lymphocytes (Figure 7).

In the next 2-3 days, the proliferation of the histo-fibroblast cell elements at the edge of the hematoma on the border with unscathed tissues began, the organization of thrombocytes in vessels, with the appearance of fibroblasts and vessels in the thrombus

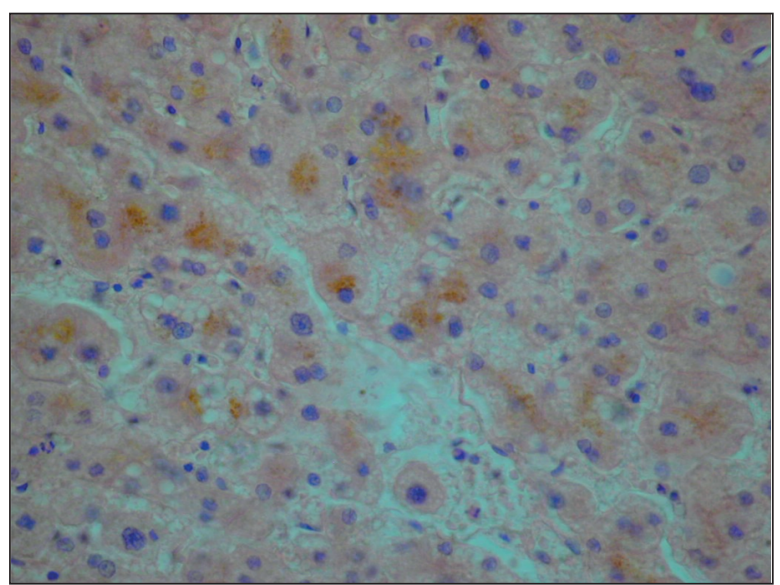

Figure 7. Hepatocytes on the periphery of the necrosis center with small- and large-vacuolar hydropic dystrophy, expressed cholestasis, and slight infiltration of lymphocytes of the liver tissues, in a 48 year-old woman, who died from mechanical trauma. The duration of injury is 2 days. Colored with hematoxylin-eosin. Scale: $\times 400$ 
was observed, histiofibroblasts - expressed cellular elements were clearly detected in torus demarcationis, which led to formation of collagen fibers with a high number of hemosiderophages. After, the hepatocytes with signs of regeneration (dual-core) on the $4-6^{\text {th }}$ days after injury appeared and the repair processes began. Cells with hypochromic nuclei and decrease of circulatory disorders signs and altered processes proofs were detected.

In old injury (more than 7 days), the hematoma was represented by hemolysed erythrocytes with a large number of destroyed leukocytes, densified collagen fibers, which clearly distinguished hematoma from damaged tissues. It was characterized by the presence of multiple grafts in the tissue of the parenchyma, which included histologic regions, delicate collagen fibers that began to form a capsule. The process of forming a capsule is quite long, it can last 1-2 months. It should also be noted that in the histological examination of liver damage in its various parts (from the site of the capsule damages, from the place of the capsule break, intact parts of the liver) there is a characteristic morphological picture, the origin of which must be thoroughly differentiated when evaluating the results 35,36 .

\section{Discussion}

Despite the large number of studies dealing with the abdominal cavity damage, the questions of time of liver injury in the absence of alcohol intoxication, as a result of simultaneous damage of one or more abdominal organs was not thoroughly studied. At histological examination, there were regular changes in parenchymal organs despite various injury time. Histological methods allow to establish the time of both one-stage and two-stage liver ruptures, in particular, the term of hematoma formation under its body capsule or in the depths of its parenchyma with a rupture or without apparent rupture of parenchyma, which begin to appear at the moment of capsule rupture in the place of the hematoma, and gradually accumulate in remote periods after an injury, which leads to diagnostic errors in medical practice. These methods are also helpful in determining the absence effect of alcohol intoxication ${ }^{4-16}$. It is necessary to differentiate the characteristic morphological picture which is revealed by the histological study of liver catarrhal hematomas (from the region of subcapsular lesions, from the places of hematomas and the capsule rupture in accordance with the location of the subcapsular hematoma, intact parts of the liver outside its primary and repeated rupture $)^{37}$. This allows to exclude or confirm the term and circumstances of caused abdominal trauma, especially in the unclear situation and in the case of repeated injury on the liver area, and also to determine the absence of alcohol intoxication ${ }^{26-30}$.

In the scientific literature ${ }^{32-34,38-39}$, we found data on the following changes: in the first hours and the first day after the trauma, at the capsule rupture blood stasis appears under the capsule, hematoma was formed with well-marked red blood cells; until the end of the second day, stasis of leukocytes in sinusoids and fibrin appear. On the $3^{\text {rd }}$ day after the injury, signs of hemolysis with the erosion of the erythrocyte contours in the center of hematoma and division of blood into plasma and unstructured detritus were observed. On the $5^{\text {th }}-6^{\text {th }}$ days, in the edges of the hematoma there were signs of organization of the fibroblasts proliferation with the wall of capillaries, which began to form a capsule. Nonetheless, the capsule was not detected 2-3 weeks after the trauma occurred.

A slightly different picture was described in sub-capsular hematomas and ruptures. In the first hours after the trauma, the contours of the hepatocytes were clear, the nuclei were preserved, the cytoplasm was well-painted; on the $2^{\text {nd }}-3^{\text {rd }}$ days, there were signs of necrosis with nucleus picnosis, weak coloration of the cytoplasm, eruptions of contours of hepatocytes and their melting. There were fragments of the Glisson capsule up to 2-3 weeks in the center of hematoma. There were areas of necrosis of hepatocytes on the hematoma edges in the liver. In the preserved parenchyma, there increased edema of the lobules center with the lumen enlargement of the central veins and sinusoids, and the uneven glycogen distribution in the hepatocyte cytoplasm. By the end of the week, there were signs of regeneration in parenchyma, in the form of hyperchromia of nuclei or binuclear hepatocytes.

\section{Conclusions}

The research results showed that the morphological features of the liver capsule breakdown allowed us to decide whether this rupture occurred directly at the moment of the injury, or it was a consequence of non-fibrotic changes in the region of accumulated hematoma. The obtained results indicate the existence of natural dynamics of the histological parameters changes in the dead who died from injuries in the absence of alcoholic intoxication, and the possibility of developing a set of criteria for assessing the establishment of time of injury to the internal organs of the abdominal cavity, in particular, the liver, in the injured and the deceased at various types of injuries taking into account the syndrome of mutual obstruction, traumatic illness, individual characteristics of the organism. 
Further research on the study of liver damage, in particular the diagnosis of the mechanism, the nature and timing of the onset of injury, in the absence of alcohol intoxication, is necessary for the development and application of prophylactic methods for injuries.

Acknowledgements. We thank all the members of the research team

\section{Compliance with Ethics Requirements:}

„The authors declare no conflict of interest regarding this article"

„The authors declare that all the procedures and experiments of this study respect the ethical standards in the Helsinki Declaration of 1975, as revised in 2008(5), as well as the national law."

$$
\text { "No funding for this study" }
$$

\section{References}

1. Banks PA, Freeman ML. Practice guidelines in acute pancreatitis. Am J Gastroenterol. 2006;101(10):2379-2400.

2. Birmes P, Escande M, Gourdy P, Schmitt L. Biological factors of post-traumatic stress: neuroendocrine aspects. Encephale. 2000;26(6):55-61.

3. Bonne O, Brandes D, Segman R, Yehyda R. Prospective evaluation of plasma cortisol in recent trauma survivors with posttraumatic stress disorder. Psychiatry Res. 2003;119(1):171-175

4. Brown MA, Casola G, Sirlin CB, Patel NY, Hoyt DB. Blunt abdominal trauma: Screening US in 2,693 patients. Radiology. 2001;218(2):352-358.

5. Browstein MR, Bunting T, Meyer AA, Fakhry SM. Diagnostic and management of blunt small bowie injury: A survey of the membership of the American Association for the surgery of trauma. J Trauma. 2000;48(3):402-407.

6. Butterfield MI, Becker M, Marx CE. Posttraumatic stress disorder in women: current concepts and treatments. Curr Psychiatry Rep. 2002;4(6):474-486.

7. Cogen H, Zohar J, Matar M. The relevance of differential response to trauma in an animal model of posttraumatic stress disorder. Biol Psychiatry. 2003; 53(6):463-473.

8. Ferrando AA. Effects of inactivity and hormonal mediators on skeletal muscle during recovery from trauma. Curr Opin Clin Nutr Metab Care. 2000;3(3):171-175.

9. Gundersen Y, Vaagenes P, Pharo A. Moderate hypothermia the inflammatory response and reduces organ injury after acute hemorrhage. Acta Anasthesiol Scand. 2001;45(8):994-1001.

10. Hawk LW, Dougall AL, Ursano RJ, Baum A. Urinary catecholamines and cortisol in recent-onset posttraumatic stress disorder after motor vehicle accident. Psychosom Med. 2000;62(3):423-434.

11. Hayrapetyan HL, Khachatryan HF, Mardanyan SS. Activity of enzymes of adenyline compounds metabolism during crash and decompression of muscle tissue. Part II. Adenosine deaminase activity at experimental crash syndrome. Med Sci Monit. 2000;6(6):1068-1076.
12. Huang Y-S, Jiang J-W, Wu G-Ch, Cao X-D. Effect of melatonin and electroacupuncture (EA) on NK cell activity, interleukin-2 production and POMC-derived peptides in traumatic rats. Acupunct Electrother Res. 2002;27(2):95-105.

13. Jacobs DG, Sarafin JL, Marx JA. Abdominal CT scanning for trauma how low can we go? Injury. 2000;31(5):337-343.

14. Kanter ED, Wilkinson CW. Glucocorticoid feedback sensitivity and adrenocortical responsiveness in posttraumatic stress disorder. Psychiatry. 2001;15(50):238-245.

15. Martinelli V. Trauma, stress and multiple sclerosis. Neurol Sci. 2000;21(2):849-852

16. McCullers DL, Sullivan PG, Scheff SW, Herman JP. Traumatic brain injury regulates adrenocorticosteroid receptor mRNA levels in rat hippocfmpus. Brain Res. 2002;947(1):41-49.

17. Monk CS, Pine DS, Charney DS. A developmental and neurobiological approach to early trauma. Semin Clin Neuropsychiatry. 2002;7(2):137-146.

18. Newport DJ, Nemeroff CB. Neurobiology of posttraumatic stress disorder. Curr Opin Neurobiol. 2000;10(2):211-218.

19. Offner PJ, Moore EE, Ciesla D. The adrenal response after severe trauma. Am J Surg. 2002;184(6):649-653.

20. Leshner AI, Mancher M (eds): Medications for Opioid Use Disorder Save Lives. Committee on Medication-Assisted Treatment for Opioid Use Disorder; Board on Health Sciences Policy; Health and Medicine Division; National Academies of Sciences, Engineering, and Medicine. Washington (DC), National Academies Press (US), 2019:180.

21. Woolf SH, Aron L, (eds).U.S. Health in International Perspective: Shorter Lives, Poorer Health. National Research Council (US); Institute of Medicine (US). Washington (DC), National Academies Press (US), 2013: 420.

22. Major Trauma: Service Delivery. National Clinical Guideline Centre (UK). London: National Institute for Health and Care Excellence (UK); 2016 Feb. NICE Guideline, No. 40. https://www.nice.org.uk/guidance/ng40/evidence/ full-guideline-pdf-2313258877 (Accessed on March 11, 2019)

23. Adam GP, Di M, Cu-Uvin S, Halladay C, Smith BT, Trikalinos TA. Strategies for Improving the Lives of Women Aged 40 and Above Living With HIV/AIDS [Internet]. Rockville (MD): Agency for Healthcare Research and Quality (US); 2016 Nov. Report No.: 16(17)-EHC040-EF. https://www.ncbi.nlm.nih.gov/books/NBK401283/ (Accessed on March 11, 2019)

24. Sapozhnikova MA. Morphology of the closed injury of the chest and abdomen. Moscow, Editing House Medicine, 1988: 160. [Russian]

25. Health, United States, 2017: With Special Feature on Mortality [Internet]. National Center for Health Statistics (US). Hyattsville (MD): National Center for Health Statistics (US); 2018. https://www.cdc.gov/nchs/data/hus/hus17.pdf (Accessed on March 11, 2019)

26. Major Trauma: Assessment and Initial Management. National Clinical Guideline Centre (UK). London: National Institute for Health and Care Excellence (UK); 2016 Feb. NICE Guideline, No. 39. https://www.nice.org.uk/guidance/ng39 (Accessed on March 11, 2019)

27. Likis FE, Sathe NA, Morgans AK, et al. Management of Postpartum Hemorrhage [Internet]. Rockville (MD): Agency for Healthcare Research and Quality (US); 2015 Apr. Report No.: 15-EHC013-EF https://www.ncbi.nlm.nih.gov/books/ NBK294465/ (Accessed on March 11, 2019)

28. Totten AM, Cheney TP, O'Neil ME, et al. Physiologic predictors of severe injury: systematic review. Rockville (MD), 
Agency for Healthcare Research and Quality (US), 2018 Apr. Report No.: 18-EHC008-EF. https://www.ncbi.nlm. nih.gov/books/NBK537450/ (Accessed on March 11, 2019)

29. Baramia NN. Surgical treatment of liver damage in case of concomitant closed thoracoabdominal injury. Clinical Surgery 2000;8:29-31.

30. Birmes P. Biological factors of post-traumatic stress: neuroendocrine aspects. Encephale 2000;26(6):55-61.

31. Babkina OP. Duplication of injuries to organs of the empty light by laboratory methods. Mauritius, OmniScriptum Publishing Group, 2018: 148 p.

32. Dubrov SO. The basic principles of intensive therapy of patients with polytrauma at an early stage. Ways of optimization. Science Rise 2015;5(4):117-123.

33. Savelyev VS. Manual for emergency surgery of the abdominal cavity. M: Triada X; 2005. 237 p.

34. Kimbar VI, Guzheedov VN, Solokhin AA. Mechanogenesis and morphology of a closed liver injury caused by blunt solid objects (mathematical evaluation). Forensic Medical Examination 2007;3:12-13.

35. Draghici T, Negreanu L, Bratu O, et al. Liver abnormalities in patients with heart failure. Arch Balk Med Union 2018;53(1):76-81.

36. Diaconu C, Balaceanu A, Morosan E. Sepsis biomarkers: past, present and future. Farmacia 2015;63(6):811-815.

37. Balaceanu A, Diaconu C, Aron G. Budd-Chiari syndrome as an initial presentation of hepatocellular carcinoma - a case report. Medical Ultrasonography 2014;16(2):172-174.

38. Brown MA, Casola G, Sirlin CB, Patel NY, Hoyt DB. Blunt abdominal trauma: Screening US in 2,693 patients. Radiology 2001;218(2):352-358.

39. Soroka AS. Rational approaches to the diagnosis of injuries and abdominal injuries in the limited conditions of medical care. Medico-biological and socio-psychological problems of safety in emergency situations 2013;1:24-27. 